\title{
Impact of Diurnal Temperature Range on Cardiovascular Disease Hospital Admissions among Chinese Farmers in Dingxi(the Northwest China)
}






\section{Abstract}

Background: Diurnal temperature range (DTR), an important index of climate change, has been widely applied in exploring its effect on cardiovascular disease (CVD). However, few studies have investigated the correlations between DTR and CVD in poor rural areas in China.

Methods: Therefore, using a distributed lag nonlinear model and a Poisson regression model, we evaluated this relationship among farmers living in the city of Dingxi (Northwest China). From 2016 to 2019, we obtained outpatient visits for CVD and meteorological data from the New Rural Cooperative Medical Insurance of Gansu Province (NRCMI) and Meteorological Science Data Sharing Service, respectively. The effects of DTR were examined in subgroups stratified by gender and age.

Results: We observed nonlinear M-patterns between DTR and CVD hospitalizations among all subgroups when DTR was at the median level (13 $\left.{ }^{\circ} \mathrm{C}\right)$. Estimated effect of a relatively low DTR $\left(5^{\text {th }}\right.$ percentile, $\left.4^{\circ} \mathrm{C}\right)$ on the hospital admissions of CVD was stronger than the effect of a relatively high DTR $\left(95^{\text {th }}\right.$ percentile, $19^{\circ} \mathrm{C}$ ). We also found that the adverse effect of DTR on CVD risk was more pronounced in females and elderly than males and younger adults at the low DTR, and vice versa at the high DTR.

Conclusions: These results could guide the local authorities to improve CVD preventive strategies in the rural areas.

\section{Background}

With the increasing concern about global climate change, temperature plays a significant role in human health. It is well-established that temperature variation during a certain period is one of the most important climatic factors related to human diseases [ $\left.{ }^{1}-4\right]$, especially cardiovascular diseases, the leading cause of death globally $\left.{ }^{2}, 6\right]$. Temperature-related environment variables have been studied as influencing factors for CVD in European US $\left[{ }^{3}\right]$, Australian[ $\left.{ }^{4}\right]$, and cities $\left[{ }^{5}\right]$. As the worldwide average temperature rise due to increases of minimum temperature, diurnal temperature range (DTR), defined as the intraday difference between maximal and minimal temperature, has been suggested as an important index of climate change. This is because it can better represent the temperature variability within one day compared with the mean temperature [ $\left.{ }^{6}\right]$. The DTR effects on CVD have been associated with the death and incidence of CVD and respiratory mortality in Japan $[7]$, Hong Kong $\left[{ }^{8}\right]$, Korea $\left[{ }^{9}\right]$, Canada $\left[{ }^{10}\right]$, and mainland China $\left[{ }^{11}\right]$. Most of these studies focused on the association between DTR and the broad categories of CVD causes of morbidity and mortality in the urban areas. Nevertheless, the farmers, who are more vulnerable to temperature change than urban residents, were not represented enough in these studies[12]. Hence, there is a need to explore the adverse impact of DTR on CVD morbidity and investigate the modifying effects of gender and age in under-development rural areas.

Dingxi is located in the Northwest of China, across two climate zones with severe climate change, a significant region in the middle of the Silk Road connecting Eurasia. Meanwhile, Dingxi, a city dominated by agriculture, has the most impoverished counties in China, with $65 \%$ of the agricultural population $\left[{ }^{13}\right]$, as show in Figure1.A prior study has reported that more severe diseases related to extreme temperature may occur in the impoverished region due to the low capacity of medical resources $\left[{ }^{14}\right]$. Thus, the association between DTR and CVD in Dingxi could help identify susceptible populations and subsequently improve cost-effective preventive strategies. Hence, we investigated the impact of high and low DTR levels on CVD hospitalization in Dingxi, China. This study stands out from previous studies by evaluating DTR effects on the CVD hospital admissions among the rural residents in one of the most impoverished areas in China. The residents of Dingxi experience greater changes in temperature leading to more likelihood of CVD.

\section{Methods \\ Study area}

Dingxi ( $\left.35^{\circ} 57^{\prime} \mathrm{N}, 104^{\circ} 57^{\prime} \mathrm{E}\right)$, a city of Gansu Province, located in Northwestern China. It is one of the poorest regions in China. It has a South temperate semihumid-middle and temperate semi-arid climate with poor precipitation and dry climate. The annual average temperature is $7^{\circ} \mathrm{C}$. The extreme maximum and minimum temperatures are $36.1^{\circ} \mathrm{C}$ in summer and $-29.7^{\circ} \mathrm{C}$ in winter, respectively. This district has a population density of 139 persons per $\mathrm{km}^{2}$ (in 2019 : population $=2969900$ persons, agricultural population $=2656500$ persons; land size $=20330 \mathrm{~km}^{2}$, cultivated land size $=5140 \mathrm{~km}{ }^{2}$ ). This district is chosen for three reasons. First, Dingxi crosses two small climatic zones, which leads to great temperature changes within one day. Second, it has the most CVD cases available to our study due to complex climate change. Third, Dingxi is a typical poverty-stricken area in China because it is situated in remote areas of China, surrounded by mountains, and has unfavorable transportation.

\section{Data collection}

The CVD hospital admission data covering the period from January 1st, 2016 to December 31st, 2019 were collected from the New Rural Cooperative Medical Insurance of Gansu Province (NRCMI), the government agency in charge of health data collection in Gansu Province. In Gansu Province, all CVD cases must be recorded to NRCMI. The records provided information on hospital admissions, age, sex, residential address, and diagnostic codes. The criteria for the code of diagnosis field base on the 10th edition of the International Classification of Diseases (ICD-10).

In term of meteorological data, data on climate variables were obtained from the China Meteorological Science Data Sharing Service. Data included daily mean temperature, minimum temperature, maximum temperature, relative humidity (\%) and atmospheric pressure (hPa). The daily mean temperature was the average of daily maximum and minimum temperatures. Temperature change was measured by the diurnal temperature range (DTR), defined as the intraday difference between maximal and minimal temperature. 


\section{Statistical methods}

The distributed lag nonlinear model (DLNM) is suitable to assess the nonlinear and hysteresis effect of exposure on public health. Several epidemiologic studies have successfully used DLNM to evaluate the association between meteorological factors and disease occurrence. To assess the independent impact of DTR on relative risks of CVD, a DLNM was applied in this study after considering potential confounders, such as mean temperature, relative humidity, and average wind speed. The model can be shown as follows:

\section{$\log \left[E\left(Y_{t}\right)\right]=\alpha+\beta\left(\mathrm{DTR}_{t, l}\right)+n s\left(\right.$ Humidity $\left._{t,} d f\right)$ $+n s\left(\operatorname{Sun}_{t}, d f\right)+n s($ Time,$d f)+$ DOW + Holiday}

Where $t$ is the day of observation $(t=1,2,3 \ldots 21)$. $E(Y t)$ represents the daily number of hospitalizations for CVD. $a$ is the intercept; is the "cross-basis" matrix of DTR in DLNM, $L$ denotes the lag days, $\beta$ indicates the vector of the coefficients for DTR. ns is a natural cubic spline for controlling potential confounding effects by fitting their $\mathrm{df}$ trend, which is the degree of freedom. The impact of the day of week and holiday are controlled by DOW and Holiday, as dummy variables, respectively.

Several scholars found that long-term trends, relative humidity, and sunshine hours make the potential contribution for influence over the relative risk of CVD in their study $\left[{ }^{15}, 20\right]$. To estimate the independent impact of DTR on outpatient visits for CVD, DLNM with natural cubic splines was applied, in which we used a $3-$ df natural cubic spline to control the effect of Humidity and Sun $\left[{ }^{16}\right]$, yet 7-df of that to remove the time tendency $\left[{ }^{17}\right]$. The df of the non-parametric smoothing terms were selected according to Akaike's information criterion (AIC) by adjusting it for each factor to minimize the AIC value [21]. We set spline knots at equally spaced values within the DTR range and at intervals in the logarithmic scale of the delays. Also, we defined DOW and Holiday variables as categorical variables to modify their influence.

The high and low DTRs were defined as the 5 th $\left(4^{\circ} \mathrm{C}\right)$ and 95 th $\left(19^{\circ} \mathrm{C}\right)$ percentiles in the DTR distribution. All the results are expressed as the relative risk change (RR) with a $95 \%$ confidence interval $(\mathrm{Cl})$ with a $1^{\circ} \mathrm{C}$ change in DTR compared with the reference DTR, $13^{\circ} \mathrm{C}$, as a median DTR distribution. Previous studies suggest that there is a lag effect of DTR on admission of CVD $\left[{ }^{18}, 24\right]$. Thus, the different day lag(lag0,1,3,5,7,14,21) were considered to estimate the hysteresis impact of DTR over cases of CVD. The effect of lagx represents the impact of DTR on CVD incidence after $x$ days.

Moreover, we conducted the risks for lags0-3, 0-7, 0-14 and 0-21 days to explore the cumulative effect of DTR on RR, in which the lag0-x was used to detect the impact of average DTR in the previous $x$ days on morbidity of CVD. Furthermore, we stratified the study group by sex (male vs. female), age (adults vs. elderly using 65 years as the cut-off point) to explore the susceptible subgroups. We used the age 65 years in the subgroups because it is China's retirement age and because people over 65 years are more likely to develop CVD.All the statistical analyses were conducted in 'dlnm' package in the RV3.4.1 statistical software. At last, we perform the Sensitivity analyses by varying the df for relative humidity and temperature, see Additional file 1 .

\section{Results}

Weather and CVD hospital admissions data in Dingxi are shown in Table 1. During the period from 2016 to 201, a total of 24940ncases occurred. On average, there were 14940 cases of CVD, of which $42 \%$ were males, and $58 \%$ were females. Patients aged $<65$ years old accounted for $58 \%$. The mean DTR was 11.76 $\left({ }^{\circ} \mathrm{C}\right)\left(\right.$ from $1.6^{\circ} \mathrm{C}$ to $26.2^{\circ} \mathrm{C}$ ), while the average temperature was $8.24^{\circ} \mathrm{C}$ (from $-17.9^{\circ} \mathrm{C}$ to $24.9^{\circ} \mathrm{C}$ ).

Table 1

Summary statistics for daily variable, and cardiovascular diseases (CVD) cases in Dingxi,

\begin{tabular}{|c|c|c|c|c|c|c|c|c|}
\hline \multirow[t]{2}{*}{ Variable } & \multirow[t]{2}{*}{ Sum } & \multirow[t]{2}{*}{ Mean } & \multirow[t]{2}{*}{ SD } & \multicolumn{5}{|c|}{ Frequency distribution } \\
\hline & & & & Min & $P(25)$ & $P(50)$ & $P(75)$ & Max \\
\hline Mean temperature $\left({ }^{\circ} \mathrm{C}\right)$ & / & 8.24 & 9.55 & -17.9 & 0.2 & 9.7 & 16.7 & 24.9 \\
\hline Relative humidity (\%) & / & 58.99 & 15.28 & 16 & 48 & 61 & 71 & 93 \\
\hline pressure & / & 810.4 & 4.17 & 797.4 & 807.3 & 810.2 & 813.3 & 823.1 \\
\hline Wind velocity $(\mathrm{m} / \mathrm{s})$ & / & 1.79 & 0.59 & 0 & 1.4 & 1.7 & 2.2 & 4.5 \\
\hline Rainfall(mm) & / & 1.11 & 3.73 & 0 & 0 & 0 & 0.1 & 54.3 \\
\hline $\operatorname{DTR}\left({ }^{\circ} \mathrm{C}\right)$ & / & 11.76 & 4.74 & 1.6 & 8 & 11.8 & 15.3 & 26.2 \\
\hline All & 24940 & 20 & 13 & 1 & 12 & 17 & 25 & 277 \\
\hline Male & 10608 & 9 & 6 & 1 & 5 & 7 & 10 & 107 \\
\hline Female & 14332 & 11 & 8 & 1 & 7 & 10 & 14 & 168 \\
\hline$<65$ years & 14568 & 12 & 9 & 1 & 7 & 11 & 16 & 172 \\
\hline$\geq 65$ years & 10372 & 8 & 6 & 1 & 5 & 8 & 11 & 105 \\
\hline
\end{tabular}


Figure2 presents the time-series distributions of outpatient visits for CVD and meteorological variables, including daily average temperature and DTR between January 2016 to December 2019 in Dingxi. As shown, the number of DTR has a seasonal tendency, while the peak of daily hospital admissions is observed in winter and spring, far higher than other months. Figure 3 shows Spearman correlations among climate. As shown, DTR was negatively correlated with WindSpeed ( $r s=-0.10)$, Rainfall ( $r s 0.41$ ), and Humidity ( $r s=-0.63$ ). There was a positive correlation between Rainfall and Humidity ( $r=0.49$ ), and between Rainfall and Temperature $(r s=0.16)$. A positive correlation was also observed between WindSpeed and Temperature. These correlations were statistically significant.

Table 2 shows the lag effect of DTR (reference value $=12^{\circ} \mathrm{C}$ ) on RR of CVD hospital admissions among sex and age subgroups. Overall, the largest RR of high DTR was detected on the current day, attenuated along the succeeding lag day, then decreased significantly after a week. This pattern was consistent among all subgroups except males. An increase of $1^{\circ} \mathrm{C}$ in DTR was associated with an increase of $1.015 \%$ in total CVD cases without a lag day (RR:1.0115, Cl:95\%).

Table 2

Relative risk of CVD cases by gender and age groups with $1^{\circ} \mathrm{C}$ increase in DTR (Reference $=12^{\circ} \mathrm{C}$, 50th percentile)

\begin{tabular}{|lllllll}
\hline $\begin{array}{l}\text { CVD } \\
\text { cases }\end{array}$ & lag0 & lag1 & lag3 & lag5 & lag7 & lag14 \\
\hline Total & $1.0116(1.0042,1.0191)$ & $1.0111(1.0042,1.0181)$ & $1.0101(1.0042,1.0161)$ & $1.0092(1.0041,1.0143)$ & $1.0082(1.0039,1.0126)$ & $1.0049(1.000 \varepsilon$ \\
\hline Male & $1.0084(1.0003,1.0167)$ & $1.0083(1.0007,1.0159)$ & $1.0079(1.0014,1.0145)$ & $1.0076(1.002,1.0132)$ & $1.0072(1.0024,1.012)$ & $1.0059(1.0014$ \\
\hline Female & $1.0122(1.0042,1.0202)$ & $1.0116(1.0042,1.0191)$ & $1.0105(1.0041,1.017)$ & $1.0095(1.004,1.0149)$ & $1.0084(1.0037,1.0131)$ & $1.0046(1.0002$ \\
\hline Adult & $1.0177(1.0074,1.0281)$ & $1.0169(1.0073,1.0266)$ & $1.0153(1.0071,1.0236)$ & $1.0137(1.0067,1.0208)$ & $1.0122(1.0062,1.0181)$ & $1.0067(1.0014$ \\
\hline Old & $1.0082(0.9974,1.0192)$ & $1.0079(0.9978,1.018)$ & $1.0072(0.9985,1.0159)$ & $1.0065(0.9991,1.0139)$ & $1.0058(0.9995,1.0121)$ & $1.0033(0.997$; \\
\hline
\end{tabular}

Figure4 shows the association between CVD risk and DTR (reference DTR=12) in sex and age subgroups. There was a nonlinear relationship (an "M-shape" pattern) between daily DTR and daily outpatient visits for CVD. The peak effect of DTR on RR is detected as DTR is $6^{\circ} \mathrm{C}$ and $17^{\circ} \mathrm{C}$, which was consistent across all the subgroups. Regarding the sex-specific effect, the RR in males was slightly higher than in females. For age-specific effect, the maximum of RR in those with age $<65$ years was observed when DTR was $17^{\circ} \mathrm{C}$ and was higher than in those with age $\geq 65$ years. On the other hand, the maximum of RR in those with age $\geq 65$ years was found when DTR was $6^{\circ} \mathrm{C}$, and was higher than their counterparts. This indicates that the elderly face more risk of CVD than the adults at the low $\mathrm{DTR}\left(\mathrm{DTR}=6^{\circ} \mathrm{C}\right)$, yet the adults suffer more risk than the elderly at relatively high $\mathrm{DTR}\left(\mathrm{DTR}=17^{\circ} \mathrm{C}\right)$.

Figure5 illustrates the cumulative effect of DTR on the number of outpatient visits for CVD at six different types of lags. The morbidity of CVD showed an "Mshape" trend with the DTR from $0^{\circ} \mathrm{C}$ to $25^{\circ} \mathrm{C}$, with extreme points observed at $6^{\circ} \mathrm{C}$ and $17^{\circ} \mathrm{C}$. There was a protective effect along DTR $>20$ compared with low DTR. Cumulative RR of DTR had a gradual enhance along the day of lag and reached the maximum with a lag of 0-21 days.

Figure6 presents the estimated effect of extreme DTR on the number of CVD admissions with a lag of 0-21days for the entire, sex-specific, and age-specific study groups (low DTR, $4^{\circ} \mathrm{C}$; high DTR, and $19^{\circ} \mathrm{C}$ ). In general, the estimated effect of DTR on the hospital admissions of CVD was stronger when DTR was low than high. At low DTR, the adverse lag effect of DTR on the risk of CVD was more pronounced for females and elderly than males and adults, while it reversed at high DTR. Similar to median DTR, low DTR affected elderly greater than adults. The effect of relatively low DTR on several CVD cases exhibited a parabola relationship over the day of lag for the entire study group. The greatest effect occurred at a lag of 14 days except for the elderly subgroups (lag:16 days). As for the impact of relatively high DTR on RR of CVD, there was a protective effect in females. The lag effect occurred after 12 days on males and 18 days in the general population. For age subgroup, the effect of high DTR on CVD cases increased at first, then decreased after 13 days for adults, yet the effect in their counterparts slightly increased along the lag day.

Figure7 depicts a three-dimensional plot to reveal the effect of DTR on the relative risk of CVD across lags. As shown, the impact of DTR on RR with a $12^{\circ} \mathrm{C}$ DTR as the reference was nonlinear. There were two opposite lag effects of DTR on RR and lag; the RR increased along with lag in relatively high DTR (17$\left.25^{\circ} \mathrm{C}\right)$, yet decreased along with lag in relatively low DTR $\left(1.6-12^{\circ} \mathrm{C}\right)$. The delayed effect of DTR on RR of CVD was not obvious at moderate DTR from $6^{\circ} \mathrm{C}$ to $17^{\circ} \mathrm{C}$. As for the impact of different DTR, the increase of relative risk for CVD was fastest on the lag of 20 days at relatively low DTR $\left(1.6^{\circ} \mathrm{C}-12^{\circ} \mathrm{C}\right)$, while the decrease of that was fastest on the current day at relatively high DTR $\left(17^{\circ} \mathrm{C}-25^{\circ} \mathrm{C}\right)$. Large DTR increase ranged from $1.6^{\circ} \mathrm{C}$ to $6^{\circ} \mathrm{C}$ had an immediate adverse effect on the number of hospitalizations for CVD, while the range from $17^{\circ} \mathrm{C}$ to $25^{\circ} \mathrm{C}$ of that had a protective effect on it.

\section{Discussion}

In this study, we examined the relationship between diurnal temperature range and the outpatient visits for CVD. There was a statistically significant association between the admission of CVD and the diurnal temperature range. An increment of $1^{\circ} \mathrm{C}$ in DTR, changing from $12^{\circ} \mathrm{C}$ to $13^{\circ} \mathrm{C}$, was associated with a $1.16 \%$ increase in RR of CVD in the entire study group $(0.84 \%, 1.22 \%, 1.77 \%$, and $0.82 \%$ in males, females, adults and elderly, respectively). These findings suggest that the effect of DTR on CVD is stronger in females than males and that the adult younger than 65 years old suffer more risk of CVD under the temperature change when the DTR at the median level.

Two factors motivated our investigation of the DTR as the factor affecting CVD in Dingxi. First, because it is located on the edge of the Loess Plateau with a large in-day temperature difference, and second because of its high incidence of CVD and cerebrovascular diseases. Many prior scholars have demonstrated a linear or nonlinear relationship between DTR and CVD. For example, shan zheng et al. investigated the effect of DTR on ischemic heart disease ER admissions 
in Beijing among elderly ${ }^{19}{ }^{19}$. In Korea, Youn-Hee et al. revealed positive linear associations between DTR and CVD ER admissions[13]. However, in Yuxi, China, Ding et al. (2015) reported a J-shaped association for the impact of DTR with cardiovascular mortality $\left.{ }^{20}\right]$. These results were inconsistent with our study as we found a nonlinear relationship ("M-shape" pattern) between daily DTR and daily number of CVD admission. More people become active and are exposed to ambient temperature at low DTR, particularly in aging people. This might have resulted in the first peak in RR of CVD. In contrast, the second peak of the relative risk of CVD could be attributed to the stronger effect of high DTR than the low one. The results found in Taiwan reported that acute coronary syndrome admissions increased rapidly when DTR exceeded a threshold of $\left.9.6^{\circ} \mathrm{C}^{21}\right]$. The impact of DTR on CVD has been reported in many previous studies. Shan Zheng reported significantly acute effects of DTR on all cardiovascular and cerebrovascular disease ER admissions among males and females living in Beijing. In Hong Kong, an increase of $1^{\circ} \mathrm{C}$ in DTR at lag days 0-3 was associated with a $1.7 \%$ increase in mortality of cardiovascular among elderly. In the United States, K. L. et al. concluded that a $10^{\circ} \mathrm{C}$ decrease in average daily temperature led to a $13 \%$ increase in fatal, incident, and recurrent coronary events in San Francisco and Sacramento (California) [22]. These results are consistent with what Danet et al. found in Northern France[23]. A recently published study conducted in Jingchang, Northwestern China, showed a positive linear correlation between DTR with systolic blood pressure and pulse pressure, but a negative linear correlation between DTR with diastolic blood pressure[24]. These findings have led to a speculation that blood pressure is a trigger in the onset of cardiovascular diseases. In addition to blood pressure, oxygen uptake, heart rate, and cardiac workload may also increase CVD risk during exposure to daily temperature ranges[25]

Studies in China[15], Korea[26], and Japan[11] have pointed out that the impact of DTR on CVD varies by age and gender, with the elderly and females being more susceptible to the negative effects of DTR. In our study, when DTR was relatively low $\left(4^{\circ} \mathrm{C}\right.$, 5 th percentile in the DTR distribution), our results became in agreement with these results. Jayeun Kim et al. have pointed that adverse effects of DTR were more pronounced in those aged $\geq 65$ years and varied according to geographic, longitudinal, climatic characteristics, and the scale of DTR $(0.33 \% ; 95 \% \mathrm{Cl}: 0.12,0.55)$ for overall all-cause mortality. In China, deaths of cardiovascular among females and elderly ( $\geq 65$ years) were more strongly associated with DTR than among males and younger people ( $<65$ years) [15]. The elderly appear to suffer more risk of CVD, probably due to increasing age, progressive reduction in the physiological ability to sense changes in body temperature, and reduction in the body's compensatory mechanisms (i.e., shiver or sweat) to regulate temperature[ $\left.{ }^{27}, 34\right]$. Regarding effect modification by gender, our results provide evidence that cardiovascular disease was greater in females than in males at small amplitude of temperature change.

Epidemiologic studies provide support to this ascertain. For example, in Korea, research conducted in six cities by Lim et al. agreed that cardiovascular disease death among females associated more strongly with DTR than among males[ $\left.{ }^{28}\right]$. Meanwhile, Yang et al. reported that women in Guangzhou (China) were consistently more sensitive to the adverse impact of DTR on total and cardiovascular mortality [29]. A previous study by Basu et al. (2009) has speculated that the differences in the effect of temperature by gender were the result of location and population $\left[{ }^{30}\right]$ That is why the impact of hot temperature on coronary events was greater for men in San Paulo, while greater for women in Mexico City $\left[{ }^{31}\right]$. Furthermore囚the research conducted in Europe by Lancet explained that clothing plays a significant role in explaining sex difference and that there is a biological difference between gender in the ability to thermoregulate[ $\left.{ }^{32}\right]$.

A novel finding in our study was that a relatively low DTR could significantly impact cardiovascular diseases in all subgroups than a relatively high DTR, which is in line with prior research in Guangzhou for investigation $\left[{ }^{33}\right]$. A small variation in daily temperature was associated with a greater risk of mortality than a large variation in daily temperature. A study in shanghai reported that the effect of extremely high or low DTR on daily mortality of CVD was stronger than that of moderate DTR (approximately equal to mean DTR) $\left[{ }^{34}\right]$. With the global temperature change and lack of awareness and measures to withstand the low temperature change, people will suffer more impact of low DTR. The decreasing trend in DTR was mainly caused by the significant increase in the minimum temperature during night-time $\left[{ }^{35}\right]$, particularly in Northeast China $\left[{ }^{36}\right]$. When encountering the drastic temperature change, most people, especially the elderly and women, should act to weaken it, such as staying at home and using heat sources $\left[{ }^{37}, 45\right]$.

Another distinctive finding of our study is that high DTR showed a protective effect of cardiovascular diseases in women and elderly compared with their corresponding categories. Also, Dindxi is dominated by agricultural development, with potatoes and winter wheat representing the main food crops. Therefore, our study population is mainly farmers, and our data were obtained from the NCMS (new rural cooperative medical system). In other studies of Southwest China, it has been reported that farmers bear more risk of mortality due to high DTR than non-farmers. Ravallion and Chen attributed these results to poor living conditions caused by low annual income, low educational level, and inferior socio-economic status $\left.{ }^{38}\right]$. Also, the agricultural work may lead to an increased high-exposure of DTR $\left.{ }^{39}\right]$. However, in the countryside of Dingxi, more than $70 \%$ of young adults go out of the city to work, and about $25 \%$ of them primarily in outdoor construction and manufacturing[17], while women and the elderly stay at home and work for farming under general conditions $\left[{ }^{40}, 49\right]$. This means that women and the elderly are more flexible and selective at work than men in the face of high-DTR weather. To be specific, in the days of high DTR, women and the elderly could not choose to go out for agricultural work which could weaken or eliminate the unfavorable effect of high DTR for them, but young men must be forced to engage in outdoor construction, since construction projects must be completed within a certain period. This led to more exposure for young men on high DTR days. A previous study has shown that a greater likelihood of DTR exposure or weaker intrinsic susceptibility factors might result in people's exposure to increased risk. Moreover, more smoking and drinking in young men, as mediating factors, may contribute to the risk of cardiovascular diseases.

To the best of our knowledge, this is the first study to investigate the association between DTR and CVD risk in the developing area of Dingxi, Northwestern China. Such a place is a backward area for China and a target for achieving universal healthcare. Our observed relation between DTR and CVD morbidity could guide the local authorities to improve CVD preventive strategies in the rural areas.

Our study has several strengths. The results were based on data from the NRCMI of Gansu Province, which is credible and validated, and NRCMI recorded the CVD events for farmers. Inevitably, our study has several limitations as well. First, we didn't include all the poverty-stricken areas, but selected a typical rural poor area as a representative. Second, the impact of personal characteristics was not considered in our analysis, such as medical history, personal behaviors, 
and living conditions due to socio-economic status. Third, it is not accurate to assume all the individuals' exposure to DTR to be similar. In addition, in-door use of heating and air-conditions would lead to measurement bias in the difference between outdoor and indoor temperature.

\section{Conclusions}

This study showed that DTR has an adverse effect on CVD morbidity, particularly in women and the elderly under low DTR. In contrast, men and elderly suffer more CVD risk than women and younger adults at high DTR. Overall, the relatively high DTR was found to exert a more unfavorable effect on residents than low DTR. These findings based on data from NRCMI of Gansu Province could be used by the local Public Health Department to better understand determinants of cardiovascular disease in underdeveloped rural areas and make decisions to improve healthcare in rural communities.

\section{Abbreviations}

DTR: Dirunal temperature range; DTR: Cardiovascular diseases;

NRCMI:New Rural Cooperative Medical Insurance of Gansu Province;

DLNM:distributed lag nonlinear model.

\section{Declarations}

\section{Acknowledgements}

This was supported by China Postdoctoral Scinece Foundation (No.2016M600827) and the National Natural Science Foundation of China(No. 71861026).

The authors would like to express their gratitude to EditSprings (https://www.editsprings.com/) for the expert linguistic services provided.

\section{Authors' contributions}

Zhai contributed to the drafting manuscript and critically revised the discussions. Qi contributed to the analysis or interpretation of data for the study and the research data is collected by Chai. All authors have read and approved the manuscript.

\section{Authors' information}

Not applicable.

\section{Funding}

This was supported by China Pstdoctoral Scinece Foundation (N0.2016M600827) and the National Natural Science Foundation of China(No. 71861026).

\section{Ethics approval and consent to participate}

The study protocol was approved by the ethics committee of Lanzhou University of Technology. The data is encrypted, the patient's name, address, and contact information are all hidden and informed consent waiver obtained from the ethics committee. The study was performed in accordance with the Declaration of Henlsinki.

\section{Consent for publication}

Not applicable.

\section{Competing interests}

The authors declare that they have no competing interests.

\section{Authors' information}

Not applicable.

\section{Data availability statements}

The datasets used and/or analysed during the current study available from the corresponding author on reasonable request. 


\section{Reference}

1. Zhan Z, Zhao Y, Pang S, Zhong X, Wu C, Ding Z: Temperature change between neighboring days and mortality in United States: a nationwide study. Sci Total Environ 2017, 584:1152-1161.

2. Zhang Y, Yu C, Bao J, Li X: Impact of temperature variation on mortality: an observational study from 12 counties across Hubei Province in China. Sci Total Environ 2017, 587-588:196-203.

3. Lichtman JH, Leifheit-Limson EC, Jones SB, Wang Y, Goldstein L: Average temperature, diurnal temperature variation, and stroke hospitalizations. J Stroke Cerebrovasc Dis 2016, 25:1489-1494.

4. Qiu H, Yu IT, Tse LA, Chan EY, Wong TW, Tian L: Greater temperature variation within a day associated with increased emergency hospital admissions for asthma. Sci Total Environ 2015, 505:508-513.

5. Guangyu Zhai, Kuan Zhang, Guorong Chai: Lag effect of ambient temperature on the cardiovascular disease hospital admission in Jiuquan, China. Air Qual Atmos Hlth 2020, 10:1007.

6. Sun JY, Shi Y, Cai XY, Liu J: Potential diagnostic and therapeutic value of circular RNAs in cardiovascular diseases. Cell Signal2020, 71:109604.

7. Fernandez-Raga M, Tomas C, Fraile R: Human mortality seasonality in Castile-Leon, Spain, between 1980 and 1998: the influence of temperature, pressure and humidity. Int J Biometeorol 2010, 54:379-92.

8. Vaneckova P, Beggs PJ, de Dear RJ, McCracken KW. Effect of temperature on mortality during the six warmer months in Sydney, Australia, between 1993 and 2004. Environ Res 2008, 108:361-369.

9. Basu R, Dominici F, Samet JM: Temperature and mortality among the elderly in the United States: a comparison of epidemiologic methods. Epidemiology $2005,16: 58-66$

10. Braganza, K.; Karoly, D.J.; Arblaster, J.M: Diurnal temperature range as an index of global climate change during the twentieth century. Geophys. Res. Lett. 2004, 31: L13217. 31(13), n/a-n/a.

11. Jayeun Kim, Jihye Shin , Youn-Hee Lim, Yasushi Honda.et al: Comprehensive approach to understand the association between diurnal temperature range and mortality in East Asia. Sci Total Environ 2016, 539:313-321.

12. Wilson W. S. Tam PhD , Tze Wai Wong MBBS. Et al: Diurnal Temperature Range and Daily Cardiovascular Mortalities Among the Elderly in Hong Kong. Arch Environ Occup H 2009, 64:202-206.

13. Youn-Hee, Lim, Yun-Chul ,Hong, Ho, Kim: Effects of diurnal temperature range on cardiovascular and respiratory hospital admissions in Korea. Sci Total Environ 2012, 417:55-60.

14. Vutcovici, M.; Goldberg, M.S.; Valois, M.F. Effects of diurnal variations in temperature on non-accidental mortality among the elderly population of Montreal. Int. J Biometeorol 2014, 58:843-852.

15. Xiaodan Zhou, Ang Zhao, Xia Meng, Renjie Chen.et al: Acute effects of diurnal temperature range on mortality in 8 Chinese cities. Sci Total Environ 2014, 493:92-97.

16. Zan Ding, Liujiu Li, Lanyan Xin: High diurnal temperature range and mortality: Effect modifification by individual characteristics and mortality causes in a case-only analysis. Sci Total Environ 2016, 544:327-634.

17. Chen Bo, DU kecheng, Feng Yang, He Zishun: Gansu Development Yearbook. China Statistical Press; 2020.

18. Zhang YQ, Xiang QQ, Yu Y, Zhan ZY, Hu KJ, Ding Z: Socio-geographic disparity in cardiorespir-atory mortality burden attributable to ambient temperature in the United States. Environ Sci PollutRes 2019, 26:694-705.

19. Zhao Q, Zhao Y, Li SS, Zhang YJ, Wang QG. et al: Impact of ambient temperature on clinical visits for cardio-respiratory diseases in rural villages in Northwest China. Sci Total Environ 2018, 612:379-385.

20. Wang QG, Zhao Q, Wang GQ. et al: The association between ambient temperature and clinical visits for inflammation-related diseases in rural areas in China. Environ Pollut 2020, 261:261.

21. Gasparrini A, Armstrong B, Kenward MG: Distributed lag nonlinear models. Stat Med 2010, 29:2224-2234.

22. Lim YH, Reid CE, Mann JK, Jerrett M, Kim H: Diurnal temperature range and short-term mortality in large US communities. Int J Biometeorol 2015, 59:1311-1319.

23. Song XP, Wang SG, Li TS. et al: The impact of heat waves and cold spells on respiratory emergency department visits in Beijing, China. Sci Total Environ 2017, 615:1499-1505.

24. Ye XF, Wolff R, Yu WW.et al: Ambient temperature and morbidity: a review of epidemiological evidence. Environ Health Perspect 2012, $120: 19-28$.

25. Shan Zheng, Minzhen Wang, Bei Li, Shigong Wang, Shilin He: Gender, Age and Season as Modififiers of the Effects of Diurnal Temperature Range on Emergency Room Admissions for Cause-Specifific Cardiovascular Disease among the Elderly in Beijing. Int. J. Environ. Res. Public Health 2016, 13:447462.

26. Zan Ding, Pi Guo, Fang Xie, Huifang Chu, Kun Li, Jingbo Pu: Impact of diurnal temperature range on mortality in a high plateau area in southwest China: A time series analysis. Sci Total Environ2015, 526:358-365.

27. Wen-Miin Liang·Wen-Pin Liu·Sze-Yuan Chou·Hsien-Wen Kuo: Ambient temperature and emergency room admissions for acute coronary syndrome in Taiwan. Int J Biometeorol 2008, 52:223-229.

28. K.L.Ebi·K.A.Exuzides·E.Lau·M.Kelsh·A. Barnaton: Weather changes associated with hospitalizations for cardiovascular diseases and stroke in California, 1983-1998. Int J Biometeorol 2004, 49:48-58. 
29. Danet S, Richard F, Montaye M, Beauchant S, Lemaire B, Graux C,et al: Unhealthy effects of atmospheric temperature and pressure on the occurrence of myocardial infarction and coronary deaths. A 10-year survey: the Lille-World Health Organization MONICA Project (Monitoring Trends and Determinants in Cardiovascular Disease). Circulation 1999, 100:e1-e7.

30. Shan Zheng, Wenzhi Zhu, Minzhen Wang, Qin Shi,et al: The effect of diurnal temperature range on blood pressure among 46,609 people in Northwestern China. Sci Total Environ 2020, 730:138987

31. Mercer,JN,Osterub,B,Tveita,T:The effect of shortterm cold exposure on risk factors for cardiovascular disease. Thromb Res 1999, 95:93-104.

32. Lim, Youn-Hee, Park, Ae Kyung, Kim, Ho: Modifiers of diurnal temperature range and mortality association in six Korean cities. Int J Biometeorol 2012, 56:33-42.

33. Bull, GM: Meteorological correlates with myocardial and cerebral infarction and respiratory disease. Br J Prev Soc Med 1973, 27:108-113.

34. Kenney, W.L, Hodgson, J.L: Heat tolerance, thermoregulation and ageing. Sports Med 1987, 4:446-456.

35. Foster, K.G., Ellis, F.P., Dore, C., Exton-Smith, A.N., Weiner, J.S: Sweat responses in the aged. Age Ageing 1976, 5:91-101.

36. Jun Yang, Hua-Zhang Liu, Chun-Quan Ou, Guo-Zhen Lin, Qin Zhou: Global climate change: Impact of diurnal temperature range on mortality in Guangzhou, China. Environ Pollut 2013, 175:131-136.

37. Adrian Gerard Barnett: Temperature and Cardiovascular Deaths in the US Elderly. Epidemi-ology 2007, 18: 369-372.

38. Barnett AG, Dobson AJ, McElduff P, et al. Cold periods and coronary events: an analysis of populations worldwide. J Epidemiol Commun H. 2005, 59:551-557.

39. Keatinge, WR; Donaldson, GC; Bucher, K: Cold exposure and winter mortality from ischaemic heart disease, cerebrovascular disease, respiratory disease, and all causes in warm and cold regions of Europe. Lancet 1997, 349:1341-1346.

40. Yuan Luo, Yonghui Zhang, Tao Liu.et al『Lagged Effect of Diurnal Temperature Range on Mortality in a Subtropical Megacity of China. Plos One 2013, 8:e55280.

41. Haidong Kan, Stephanie J. London, Honglei Chen: Diurnal temperature range and daily mortality in Shanghai, China. Environ Res 2007, $103: 424-431$.

42. Xue W, Guo J, Zhang Y et al: Decliming diurnal temperature range in the North China Plain related to environmental changes. Clim Dyn 2019, 52:61096119.

43. Shen X, Liu B, Li G, Wu Z, Jin Y, Yu P, Zhou D: Spatiotemporal change of diurnal temperature range and its relationship with sunshine duration and precipitation in China. J Geophys Res-Atmos 2014, 119:163-179.

44. Seretakis D, Lagiou P, Lipworth L, Signorello LB, Rothman KJ, Trichopoulos D: Changing seasonality of mortality from coronary heart disease. JAMA.1997, 278:1012-1014.

45. Crawford VL, McCann M, Stout RW: Changes in seasonal deaths from myocardial infarction. QJM. 2003, 96:45-52.

46. Ravallion, M., Chen, S: China's (uneven) progress against poverty. J. Dev. Econ 2007, 82:1-42.

47. Mutekwa, V: Climate change impacts and adaptation in the agricultural sector: the case of smallholder farmers in Zimbabwe. Journal of Sustainable Development in Africa 2009, 11: 237-256.

48. Limei, Yang: Research Report on the Cultivation of New Professional Farmers in Dingxi City. Agricultural Science and Technology and Information 2017, 01:85-88.

49. Yunfang Zhang: Study on the structure and influencing factors of peasant household income in Dingxi City. PhD thesis. Lanzhou University, Economics and Management Science; 2014.

\section{Figures}

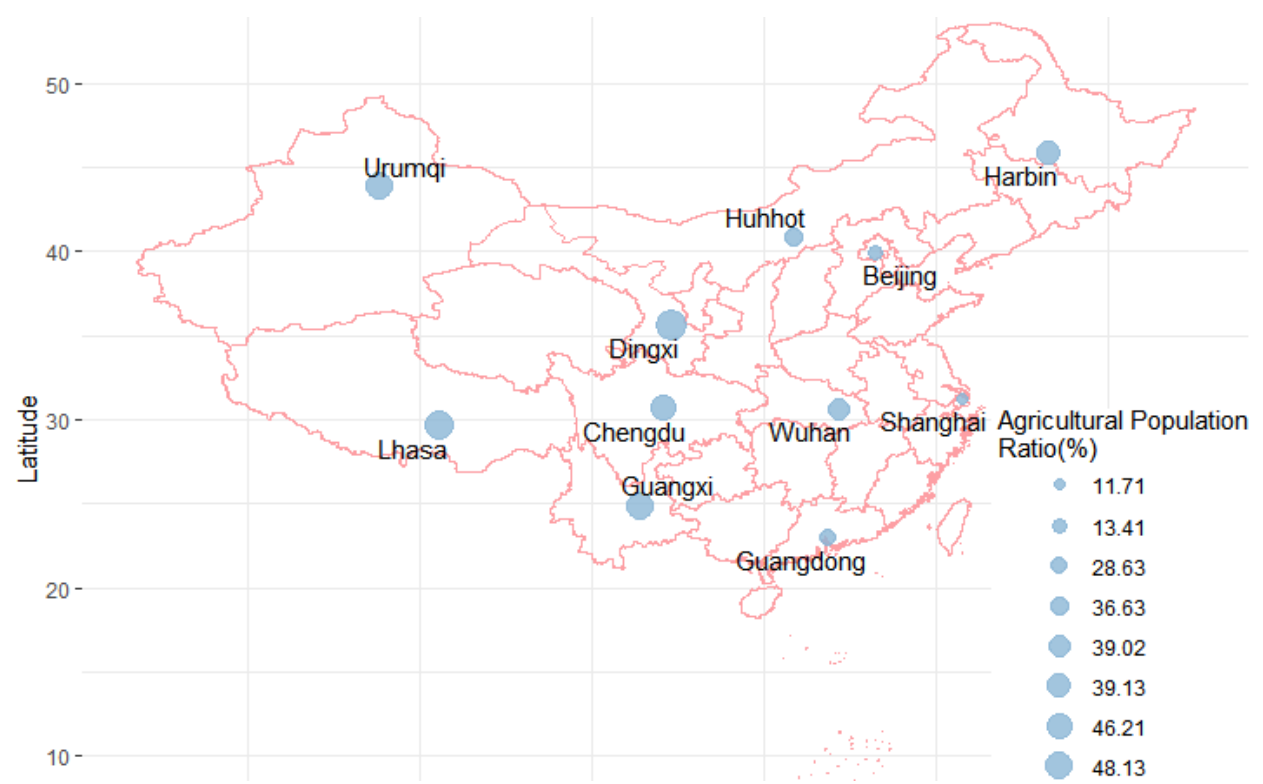

Page $8 / 13$ 
Figure 1

Proportion of agricultural population in Dingxi and major cities in China. Note: The designations employed and the presentation of the material on this map do not imply the expression of any opinion whatsoever on the part of Research Square concerning the legal status of any country, territory, city or area or of its authorities, or concerning the delimitation of its frontiers or boundaries. This map has been provided by the authors.
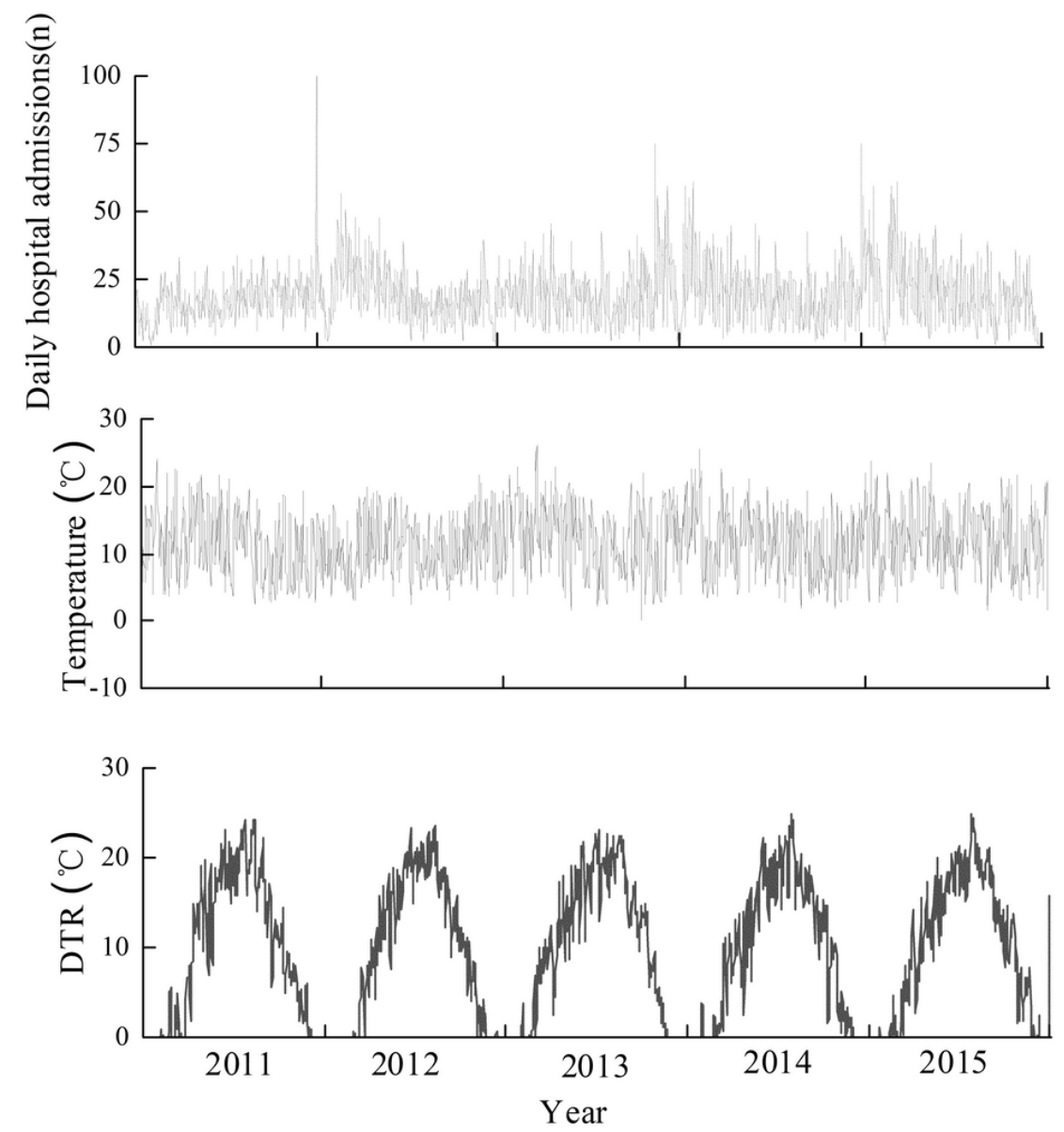

\section{Figure 2}

Times series of daily, DTR and hospital admissions of CVD. 


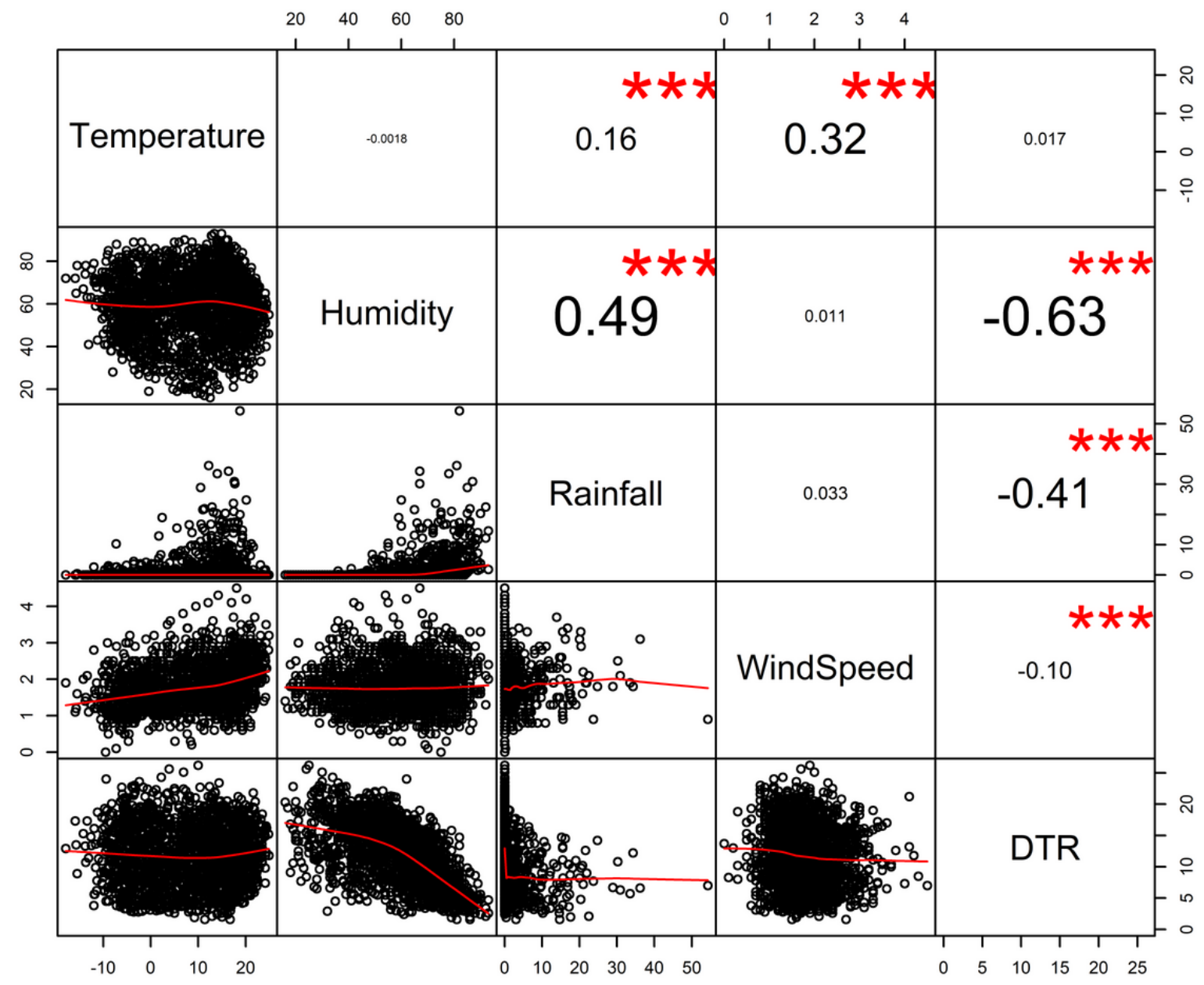

Figure 3

Spearman correlation coefficients between DTR and other weather elements. *significant level of 0.1 , **significant level of 0.05 and *** significant level of 0.01 ; The size of the numeric font represents the strength of the correlation. 

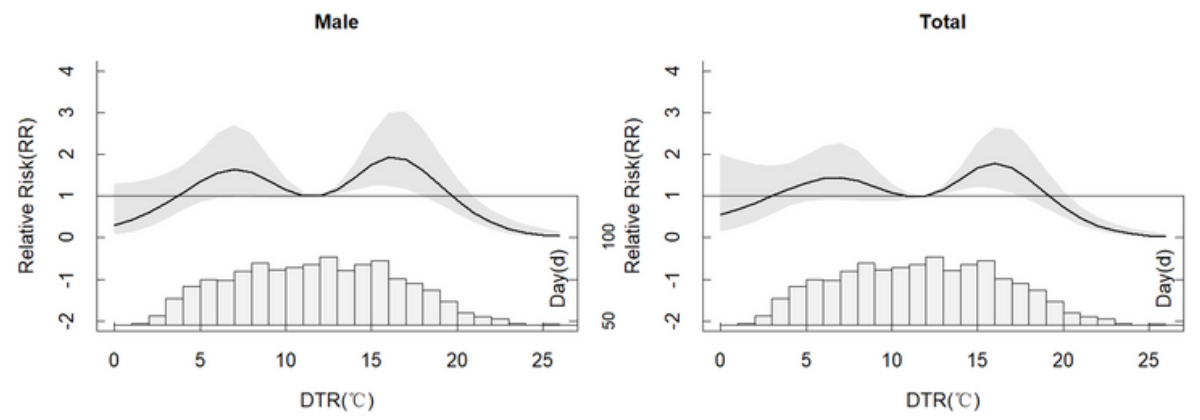

Female

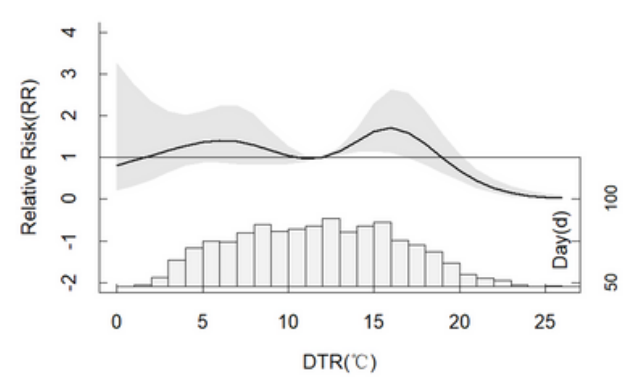

\section{Figure 4}

Estimated lag0-day effect of DTR on hospital admissions of CVD for subgroups.

lag $=0$

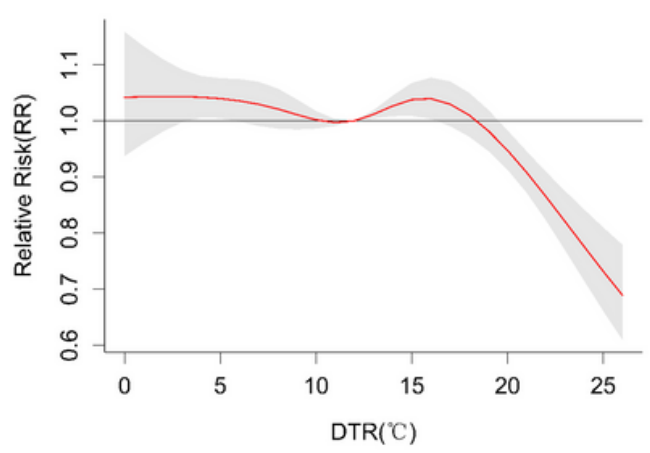

lag0-7

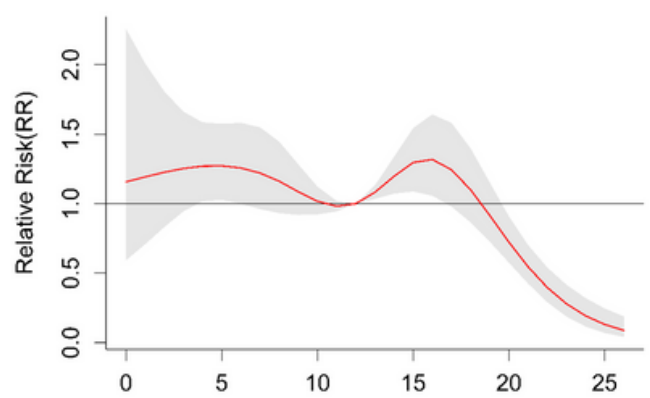

lag $=0-3$

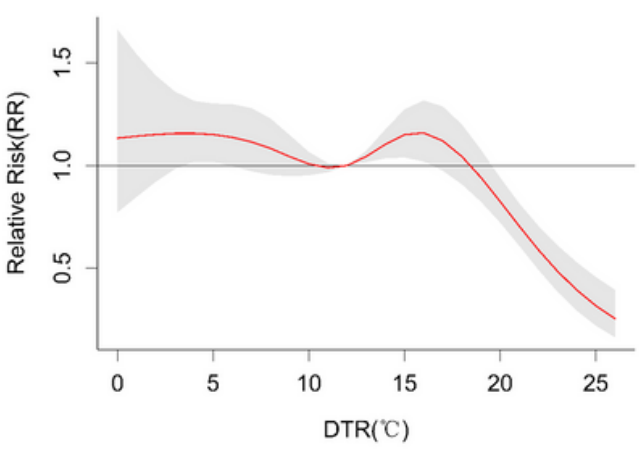

lag0-14

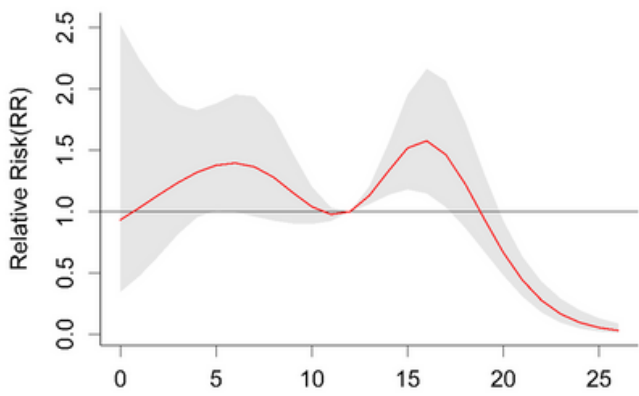

$<65$ years

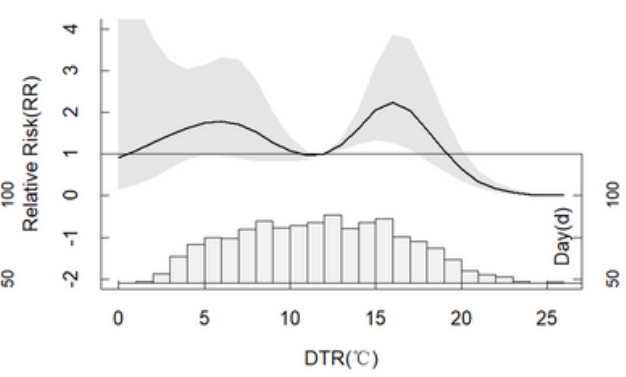

$\geq 65$ years

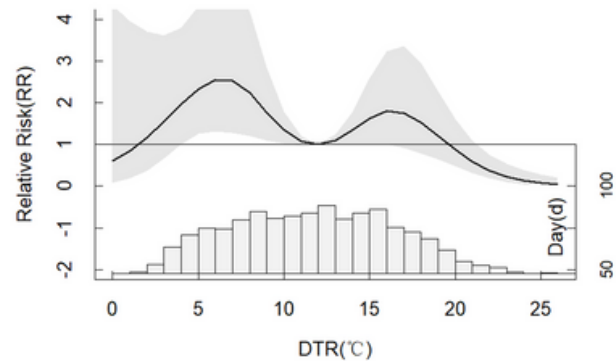

Figure 5

Cumulative effect of DTR on hospital admissions of CVD at six different types of lags. 

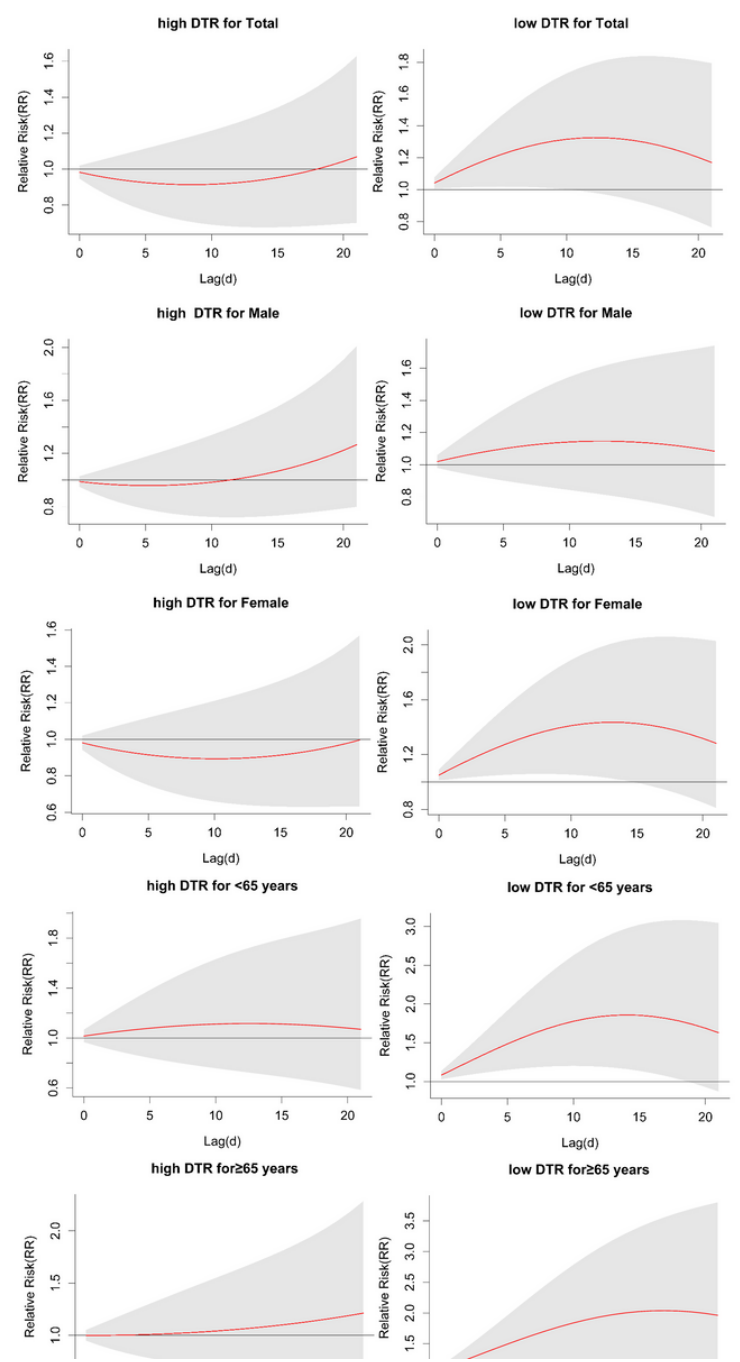

\section{Figure 6}

Estimated lag effect of extreme DTR on hospital admissions of CVD. 


\section{D graph temperature effect}

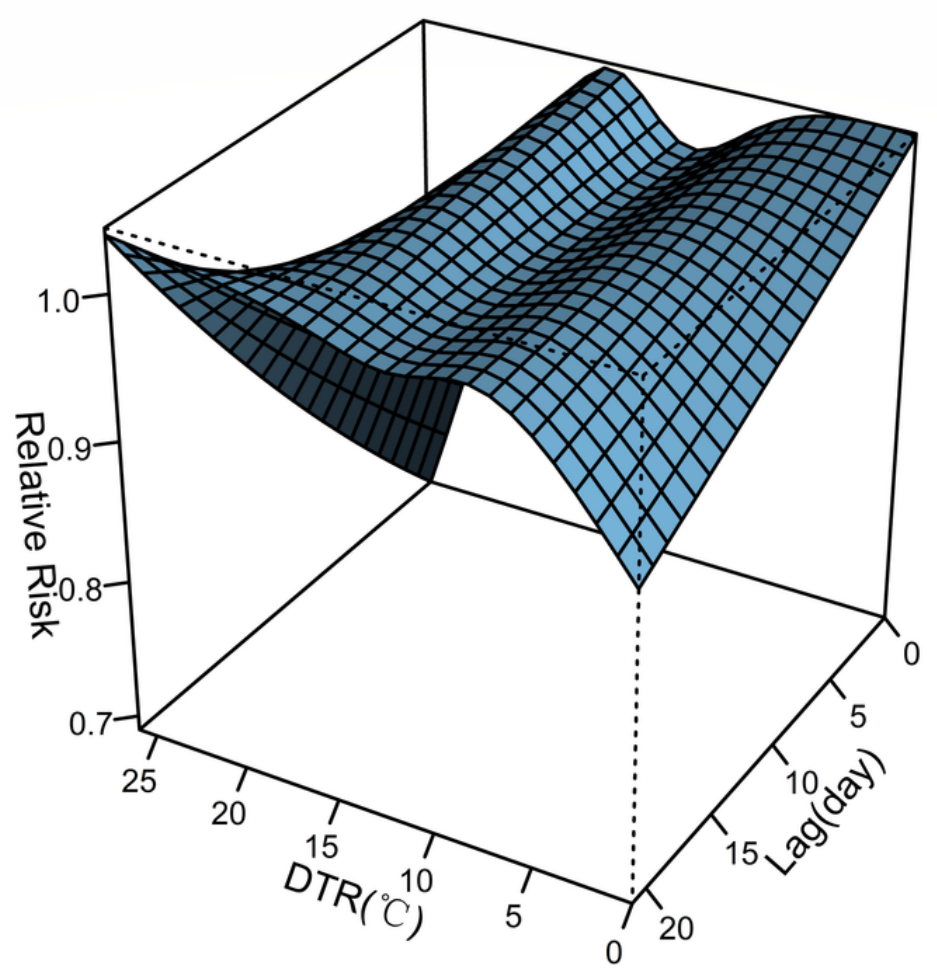

Figure 7

Three-dimensional plot of the relationship between DTR and CVD hospital admission over 21 lag days.

\section{Supplementary Files}

This is a list of supplementary files associated with this preprint. Click to download.

- FigureS1.zip 